\title{
Reseña \\ "La de-construcción curricular" de Nelson López Jiménez
}

\section{Graciela Amara de Ochoa}

\section{$\boldsymbol{N}$}

es por casualidad que en nuestro país, en los diferentes escenarios y eventos donde se hable sobre currículo, donde se piense su transformación, o donde se discutan alternativas pedagógicas y de formación, aparezcan los nombres de Nelson López y de Mario Díaz. Podríamos decir que se ha vuelto común, o más bien necesaria, la presencia de estos profesores, bien sea física o a través de sus escritos.

Tampoco es casual que cuando preguntamos acerca de qué alternativas proponer para superar el carácter fragmentado, jerárquico, insular, teorizante, memorístico, y descontextualizado de la mayoría de nuestros currículos, aparezca el Programa de Acción Curricular Aternativa -PACA-, que en el lenguaje cotidiano de educadores e investigadores, se le nombra como el modelo de los núcleos temáticos y problemáticos.

No es por casualidad que en los programas en que me ha correspondido actuar como evaluadora externa en los procesos de acreditación, el currículo, ya asumido como objeto de reflexión, o como campo específico de las especializaciones en educación, o como expresión de los arreglos instruccionales y regulativos de las instituciones, o como factor crítico en la calidad de los programas que se examinan, estén presentes los conceptos, planteamientos y perspectivas que Nelson ha venido presentando a la comunidad educativa desde hace por lo menos 15 años, cuando desde su condición de profesor y decano de la Facultad de Educación de la Universidad Surcolombiana, comenzó a interpelar el sentido y la calidad de la formación de los maestros.

La producción intelectual del profesor López, que hoy registra un importante número de libros, artículos y ponencias, presentados en el país y en el exterior, es el resultado de un paciente y sostenido trabajo investigativo; pero principalmente es producto del diálogo, el análisis y la discusión que ha mantenido con cientos de docentes, administrativos e investigadores, así como de las experiencias de acompañamiento y de asesoría en diferentes instituciones de educación básica, media y superior, pudiendo así poner a prueba sus hipótesis, recogiendo las singularidades sobre la dinámica curricular, descubriendo los obstáculos que supone la transformación en la instituciones. 
Nos hemos acostumbrado a través de los escritos del profesor López a pensar en las posibilidades de re-construir y re-significar la cultura académi$\mathrm{Ca}$, interviniendo de fondo la cultura curricular; a concebir el currículo como un proceso eminentemente participativo e investigativo, en cuyo vértice se encuentra el replanteamiento del proceso formativo; a reconocer que estas transformaciones son sólo posibles si ocurren cambios en los principios organizativos del conocimiento, cambios en el rol y la identidad de los agentes pedagógicos y cambios en las prácticas pedagógicas centradas en el aprendizaje.

Nelson nos ha acostumbrado a que centremos nuestros esfuerzos y preocupaciones en cómo cambiar los actuales currículos verticalistas, enciclopédicos, ahistóricos, carentes de formación investigativa, para tranformarlo en

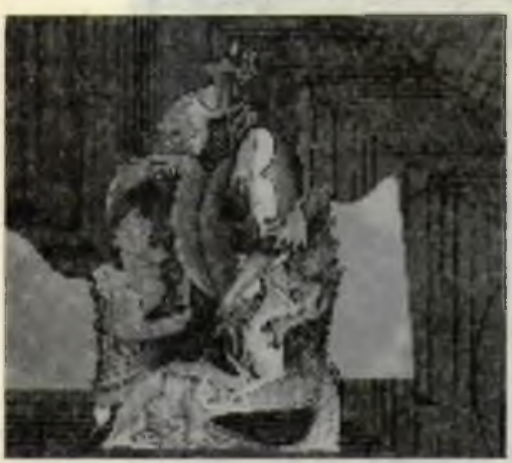
currículos integrados que transformen los límites entre espacios, tiempos, actos y formas de conocimiento: en una palabra, a re-configurar la práctica curricularya recomponer la función formativa.

Pero ahora, con su nuevo libro el profesor López nos está cambiando los términos de la invitación y nos llama a hacer una "de-construcción curricular", a des-componer y dislocar las estructuras curriculares y de formación, a des-sedimentar los significados de los conceptos, prácticas y normas que se han venido acogiendo o imponiendo a colocar bajo la duda, la sospe- cha y la interrogación creadora lo que estamos haciendo y proponiendo, a que realicemos lecturas de lo no manifiesto, de lo oculto, pero no por ello, menos real.

Se me ocurre que lo que Nelson nos plantea en su nuevo libro, bien podría denominarse una perspectiva sociológica del currículo al develar las estructuras de poder y los principios de control social que subyacen en los mecanismos de selección, clasificación, distribución, transmisión y evaluación de los conocimientos que se han considerado como válidos y necesarios en el proceso de socialización a través de la educación, y que subyacen, además, en las formas particulares en que las instituciones educativas definen y organizan las relaciones sociales que se dan hacia su interior. Encontramos, en este sentido una mirada ético-política del currículo.

También podría decir que su libro invita a adoptar una perspectiva crítico-analítica, que incluso me atrevería a referir de guiño psicoanalítico, al buscar en la identidad del profesional que se pretende formar, un proceso de construcción intersubjetiva que compromete a todos los actores involucrados en el proceso académico; a ver las fisuras y las grietas que hay entre lo que las instituciones dicen que son $y$ hacen con lo que efectivamente realizan (esquizofrenia institucionall); a sospechar de la aparente objetividad y neutralidad de las normas y regulaciones tanto internas como externas que hemos venido aceptando y aplicando para evaluar la calidad de los programas.

Encontramos, igualmente, invitación para que, desde una perspectiva lingüística, o más propiamente semán- 


\section{7}

Paideia Surcolombiana

tica, re-descubramos nuevos sentidos y significados en los discursos institucionales, a re-significar la experiencia humana, grupal e institucional desde las huellas y marcas que deja la cotidianidad del quehacer educativo.

Desde estas ópticas el profesor López plantea un interesante cuestionamiento a lo que viene sucediendo con los procesos de modernización curricular a la luz de los imperativos y exigencias de los modelos de acreditación previa y acreditación voluntaria.

Pregunta si el sometimiento a un mismo modelo de acreditación, en el que todos los programas deben responder a las mismas exigencias, no está poniendo en peligro la singularidad y la diferencia entre programas e instituciones, si la prescripción que hizo el Estado en el Decreto 272/98 al declarar la Pedagogía como disciplina fundante de los programas de educación y al ordenar la existencia de cuatro componentes en dicha disciplina, no borra de facto los distintas paradigmas y posturas que a nivel nacional e internacional se han formulado en torno a la pedagogía a través de los tiempos. Estas dos preguntas al menos, ponen en tensión la relación entre autonomía institucional y control estatal.

También el profesor López pregunta si los cambios o ajustes curriculares que han resultado de los procesos de autoevaluación, son más de forma, de procedimiento, de operación, y muchas veces de diagramación del semáforo curricular, dejando el fondo incólume, sin la reflexión epistemológica sobre las ciencias y disciplinas que convergen en la formación profesional, sin reflexionar los cambios realizados en torno a los principios organizativos del conocimiento, sin tocar los discursos de las asignaturas, los modelos pedagógicos, las formas de evaluación. ¿No será, se pregunta el autor, que al discurso pedagógico institucional se le han hecho algunos toquecitos para que se adecue al discurso pedagógico oficial? Estas son preguntas que no solo nos evidencian una tensión entre tradición e innovación curricular, sino que nos colocan en guardia ante la sospecha que formula el autor: “¿No será que bajo el pretexto de la acreditación, se vienen propiciando una serie de cambios para que todo quede igual?"

Mientras en la mayoría de las instituciones encontramos discursos progresistas sobre la formación integral, al examinar sus prácticas pedagógicas se encuentra que éstas siguen soportadas en el fraccionamiento, en lo insular, en la separación entre investigación y docencia, en la agregación de asignaturas y de profesores, porque no existe un principio de interdisciplinariedad y porque los patrones de demarcación en áreas, departamentos y facultades son fuertes y rígidos. Estas situaciones nos ponen frente a otras dos tensiones esenciales: Por un lado. la tensión entre una cultura individualista que ha encubado micro poderes, feudos y propiedades privadas sobre las asignaturas y una cultura por desarrollar, fundada en el trabajo colectivo y asociado, en el debate y la argumentación; y por otro lado, la tensión entre las diferencias que de suyo 


\section{Universidad Surcolombiana}

mantienen las comunidades científicas y disciplinarias y los consensos o acuerdos que se buscan entre ellas.

Otra tensión que nos invita Nelson a examinar es la tensión entre el campo de producción de los conocimientos y el campo de reproducción de los conocimientos, y que en última instancia, traducen la tensión entre investigación y docencia. Aquí entran en escena dos fuerzas: de una parte las exigencias discursivas y metodológicas de los saberes con sus lenguajes, reglas de construcción y de validez especifica (el poder epistemológico): y de otro lado las formas de recontextualización o de transmisión de estos saberes (el poder pedagógico) que van - bien a privilegiar una reproducción de los conocimientos, o bien a impulsar una des-sedimentación de la arquitectura conceptual, a conocer cómo se construyó un determinado conocimiento para luego poderlo re-construir, aplicar y transferir, pero desde una posición problematizadora y crítica.

Finalmente, quisiera referirme a dos planteamientos que hace Nelson, que me parece son el producto de una decantación reflexiva de varios de sus escritos anteriores, de gran valor por la claridad con que los formula y que nos hace aterrizar en la arena movediza y compleja de la dinámica curricular.

El primer planteamiento es que la transformación de la cultura académica presupone la noción de formación. El proceso formativo es concebido como la integración entre un campo de problemas con un campo de conocimientos. En esta formulación, el campo de conocimientos constituye el fundamento (teórico y metodológico) básico para la comprensión y solución de los problemas que se seleccionan para efectos de la formación; a su vez, el campo de los problemas actúa selectivamente sobre los conocimientos básicos que se requieren, inquiriendo por fundamentos, causas, razones, explicaciones, relaciones. Este es el planteamiento que considero abre las opciones de pensar el diseño y la organización del currículo en forma diferente a la tradicional organización por asignaturas.

El segundo planteamiento es la necesidad de convertir los intereses regulativos en piedra angular de la formación, esto es, la de insertar a los estudiantes en las formas legítimas de comportamiento, carácter, juicio, de criterio que ilustre e ilumine sus acciones; de formar a los estudiantes con una conciencia de su responsabilidad ante sí mismos y ante la sociedad, de su obligación y compromiso en la construcción de un futuro de país, en la consecución de un clima moral centrado en la dignidad humana, en el valor de la vida, en la tolerancia y el respeto, en principios éticos y estéticos. Este es el planteamiento que traduce, con gran nitidez, la función simbólica y la dimensión ético-política del currículo que ha insistido el autor en develar $y$ desarrollar, y que en muchas ocasiones se ve debilitada por la ausencia de una mirada integradora del hombre, de la educación y de la sociedad para la cual estamos formando.

La brevedad en mi presentación de este libro sobre "La De-construcción Curricular" que hoy tengo el orgullo de presentar, no sólo por la riqueza y valor de su contenido, por las dudas que nos aquejan y las alternativas que nos presenta, sino por la admiración y el cariño que le profeso al maestro Nelson López, quedará ampliamente superada por la lectura cuidadosa y vivificante que estoy segura ustedes realizarán. 


\section{NURY ANDREA MLINOZ}

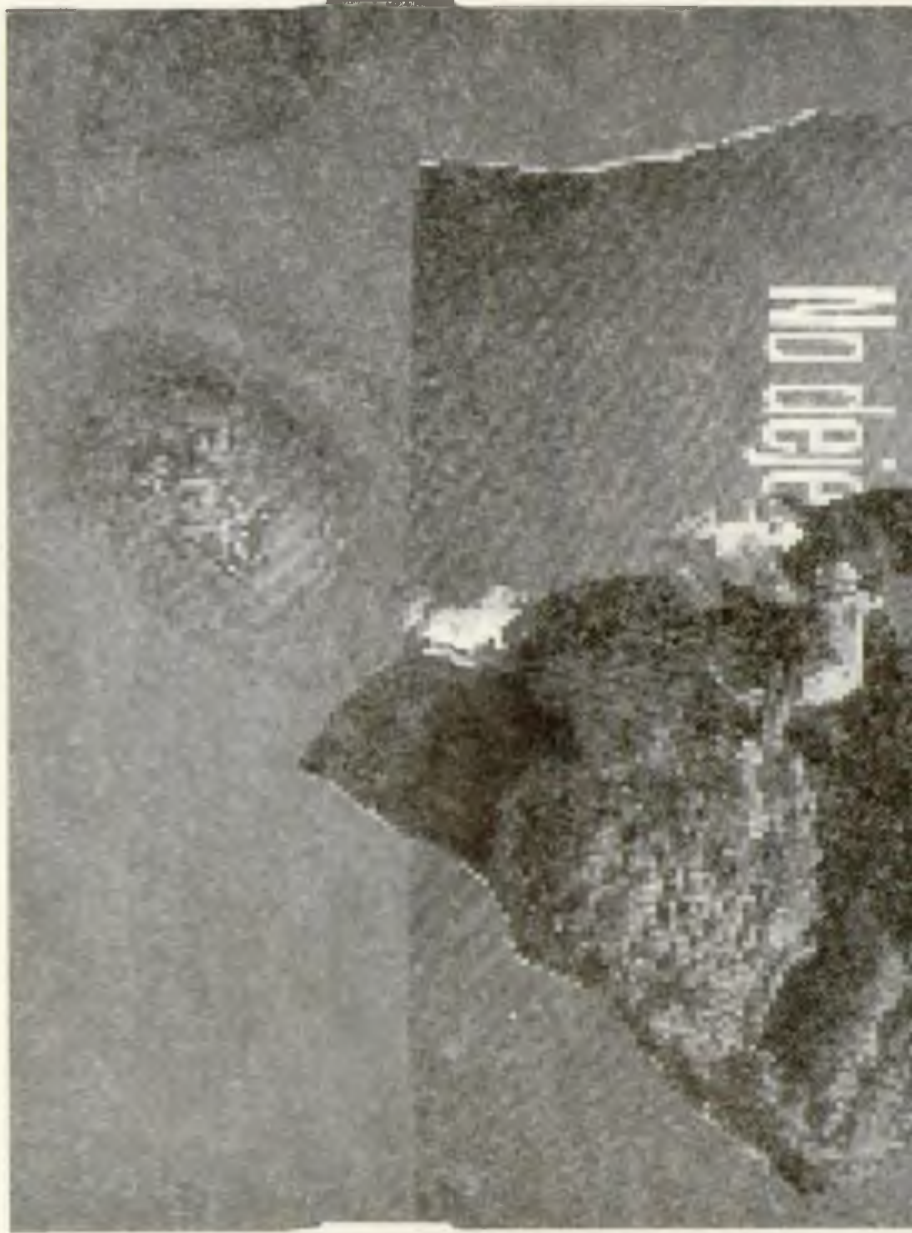




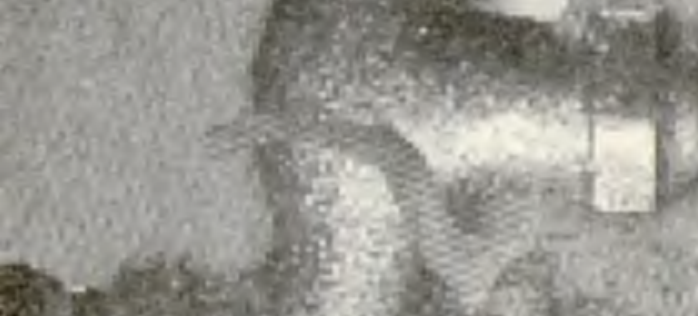

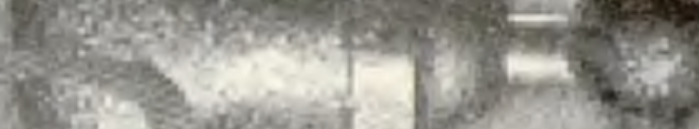

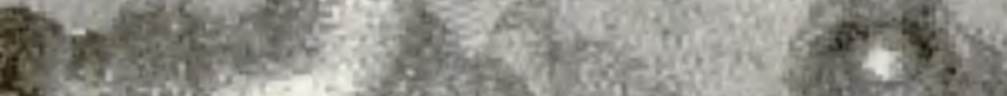

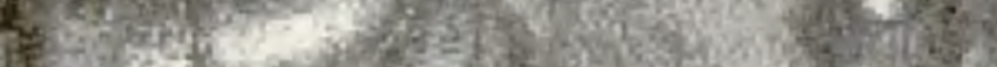
it

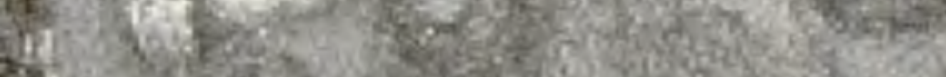

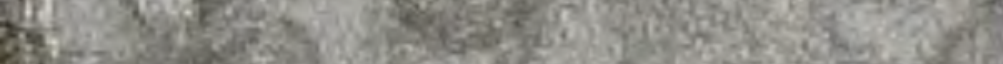

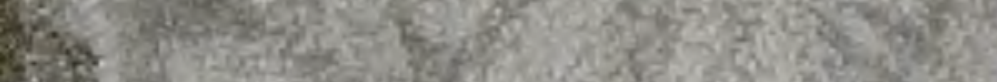

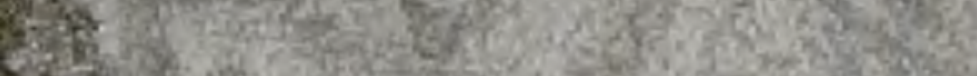

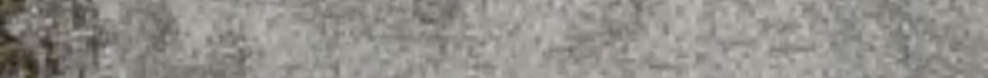

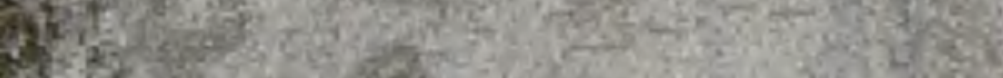
tix to

(1)

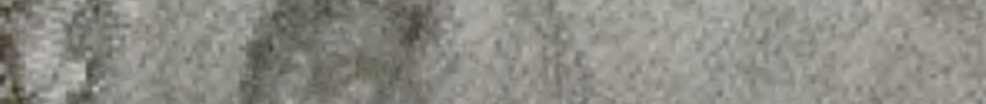
? 